\section{KẾT LUÂ̂N}

Qua nghiên cứu trên 30 bệnh nhân được phẫu thuật nội soi điều trị hẹp khoang dưới mỏm cùng vai với thời gian theo dõi trung bình sau mổ $15,8 \pm 9,8$ tháng cho thấy phẫu thuật an toàn, không có biến chứng sau mổ. Các bệnh nhân đều cải thiện mức độ triệu chứng đau và chức năng khớp vai một cách rõ rệt và người bệnh hài lòng với kết quả điều trị.

\section{TÀI LIÊU THAM KHẢO}

1. Creech JA, Silver S. Shoulder Impingement Syndrome. In: StatPearls [Internet]. StatPearls Publishing; 2020.

2. Harrison AK, Flatow EL. Subacromial impingement syndrome. JAAOS-Journal of the American Academy of Orthopaedic Surgeons. 2011;19(11):701-708.

3. Charles S, Neer I. Anterior acromioplasty for the chronic impingement syndrome in the shoulder: a preliminary report. JBJS. 1972;54(1):41-50.

4. McLaughlin HL. Lesions of the musculotendinous cuff of the shoulder: I. The exposure and treatment of tears with retraction. JBJS. 1944;26(1):31-51.
5. Noud PH, Esch J. Complications of arthroscopic shoulder surgery. Sports medicine and arthroscopy review. 2013;21(2):89-96.

6. Marecek GS, Saltzman MD. Complications in shoulder arthroscopy. Orthopedics. 2010; 33(7):492-497.

7. Husby $T$, Haugstvedt J-R, Brandt M, Holm I, Steen $\mathbf{H}$. Open versus arthroscopic subacromial decompression A prospective, randomized study of 34 patients followed for 8 years. Acta Orthopaedica Scandinavica. 2003;74(4):408-414.

8. Lindh $\mathbf{M}$, Norlin R. Arthroscopic subacromial decompression versus open acromioplasty A twoyear follow-up study. Clinical Orthopaedics and Related Research®. 1993;290:174-176.

9. Davis AD, Kakar S, Moros C, Krall Kaye E, Schepsis AA, Voloshin I. Arthroscopic versus open acromioplasty: a meta-analysis. The American journal of sports medicine. 2010;38(3):613-618.

10. Odenbring $S$, Wagner $P$, Atroshi I. Longterm outcomes of arthroscopic acromioplasty for chronic shoulder impingement syndrome: a prospective cohort study with a minimum of 12 years' follow-up. Arthroscopy: The Journal of Arthroscopic \& Related Surgery. 2008;24(10): 1092-1098.

\title{
MộT Số YẾU TỐ TÁC ĐộNG ĐẾN NHÂN VIÊN CỦA BÊ̂NH VIÊ̂N BỆNH NHIỆT ĐỚI TRUNG ƯƠ'NG VÀ BẾNH VIÊ̂N ĐA KHOA NINH BÌNH TRONG DICH COVID-19
}

Trần Thị Len', Lê Anh Tuấn², Bùi Thanh Thúy², Phạm Anh Tùng², Trần Tho Nhị ${ }^{3}$, Trần Thị Thanh Hương ${ }^{3,4}$

\section{TÓM TẮT}

Một nghiên cưu định tính qua các cuộc phỏng vấn sâu với nhân viên y tế (NVYT) làm việc tại Bệnh viện Bệnh nhiệt đới Trung ương và Bệnh viện đa khoa tỉnh Ninh Bình trong thời điểm bênh viện tiếp nhân bênh nhân COVID-19 năm 2020 nhằm đánh giá tác động tích cực và tiêu cực đến công việc của họ. Yếu tố ảnh hưởng tích cực đến công việc của NVYT là trách nhiệm và đạo đức nghề y; chuyên môn; mối quan hệ xã hội như hỗ trợ từ gia đình, đô̂ng nghiệp, sự hợp tác của bệnh nhân và chính sách, hỗ trợ nhà nước, xã hội. Yếu tố tác động tiêu cực là gia đình có con nhỏ; không làm chuyên môn và sự kỳ thị của xã hội. Cân tăng cường hơn nữa những hỗ trợ về tâm lý, vật chất

${ }^{1}$ Bệnh viện Phụ sản Trung ương

2Viện Vệ sinh dịch tễ Trung ương

${ }^{3}$ Đại học Y Hà Nội

"Viện Ung thư quốc gia, Bệnh viện K

Chịu trách nhiệm chính: Trân Thị Len

Email: tranlen22121995@gmail.com

Ngày nhận bài: 10.5.2021

Ngày phản biện khoa học: 28.6.2021

Ngày duyệt bài: 9.7.2021 cho nhân viên và người nhà của họ nhằm nâng cao chất lượng công việc và đời sống tinh thần của NVYT trong thời kỳ chống dịch. tác động.

Tư khóa: Nhân viên bệnh viện, COVID-19, yếu tố

SUMMARY
FACTORS AFFECTING HEALTHCARE
WORKERS OF NATIONAL HOSPITAL OF
TROPICAL DISEASES AND NINH BINH
PROVINCIAL GENERAL HOSPITAL UNDER
COVID-19 PANDEMIC
A qualitative study using in-depth interviews with staff working at National Hospital of Tropical Diseases (NHTD) and Ninh Binh Provincial General Hospital when the hospitals providing treatment services for COVID-19 patients in 2020 to explore the positive and negative impacts on healthcare workers during the COVID-19 pandemic. Factors positively affected the healthcare workers were responsibility and ethics; professional issues; social relationship such as support from family, colleagues, patient cooperation and government policy and social support. Factors negatively impacted were family having baby; nonprofessional staff and stigma. It is necessary to further 
strengthen psychological and material support for employees and their family members to improve the quality of work and spiritual life of medical staff during the anti-epidemic period.

Keywords: Healthcare workers, COVID-19, impact factors.

\section{I. ĐẶT VẤN ĐỀ}

Tính đến ngày 24/05/2021, trên toàn câu đã có 167.347 .213 ca nhiếm và 3.474 .699 ca tử vong do COVID-19 [1]. Con số này đã cho thấy mức độ nguy hiểm và diễn biến phức tạp của dịch bệnh COVID-19 trên toàn thế giới. Nhiều nghiên cứu đã ghi nhận về tỷ lệ kiệt sức cao của NVYT cả trước và trong đại dịch dao động từ $20 \%$ đến $81 \%$ [2]. Các cán bộ của Việt Nam tham gia công tác phòng chống COVID-19 không những đối mặt với nguy cơ cao nhiễm bệnh, sự quá tải của công việc mà còn dễ gặp phải các triệu chứng tâm lý và triệu chứng tâm thân khác nhau. Trước những khó khăn này, thành công của Việt Nam trong đại dịch COVID-19 không thể không nhắc đến sự hy sinh và vất vả của đội ngũ NVYT. Từ đó Nhà nước, chính quyên, người dân đã có những hỗ trợ dành cho NVYT với mong muốn giúp đõ động viên họ trong thời gian khủng hoảng này. Tại một số nước đã ghi nhận những tác động tiêu cực từ phía xã hội, chính sách,... đến NVYT. Tuy nhiên tại Việt Nam, chưa có các nghiên cứu cụ thể về các yếu tố tác động ảnh hưởng đến công việc của NVYT trong đại dịch COVID-19. Chính vì vậy, nghiên cứu này được triển khai nhằm phát hiện và làm rõ các yếu tố này để cải thiện và nâng cao sức khỏe của NVYT, góp phân vào thành công chiến thắng đại dịch.

\section{II. ĐỐI TƯƠNGG VÀ PHƯƠNG PHÁP NGHIÊN CỨU}

2.1. Đối tượng nghiên cứu. Nhân viên bệnh viện, bao gồm cả cán bộ chuyên môn và nhân viển chức năng. Cụ thể 15 nhân viên gồm: 3 bác sĩ (BS) trực tiếp điều trị bệnh nhân COVID19; 6 điều dưỡng (ĐD) trức tiếp chăm sóc bênh nhân COVID-19; 3 nhân viên khác có phơi nhiễm với COVID-19 bao gồm lao công, nhân viên phiên dịch; 3 điều dưỡng không tiếp xúc với bệnh nhân nhiễm COVID-19.

2.2. Thiết kế nghiên cứu: Nghiên cứu mô tả cắt ngang, thu thập thông tin định tính thông qua phỏng vấn sâu.

2.3. Thời gian và địa điểm nghiên cứu. Nghiên cứu được thực hiện tại Bệnh viện Bệnh nhiệt đới Trung ương và Bệnh viện đa khoa tỉnh Ninh Bình, từ tháng 6 đến tháng 8 năm 2020 (từ lúc bệnh viện tiếp nhận bệnh nhân điều trị COVID-19 đầu tiên).
2.4. Quy trình thu thập số liệu và xử lý số liệu. Quy trình thu thập số liệu định tính được tiến hành đông thời cùng với quá trình phơng vấn định lượng trong đề tài về "Thực trạng stress, lo âu, trâm cảm của nhân viên y tế trong đại dịch COVID-19". Số liệu định tính: Các cuộc phơng vấn sâu được ghi âm bằng máy ghi âm. Sau đó các file ghi âm này được gõ ra và đánh máy vào file word. Mã hóa và sắp xếp các thông tin theo chủ đề nghiên cứu. Cuối cùng các thông tin được tổng hợp và rút ra kết luận kèm theo trích dấn tiêu biểu.

2.5. Đạo đức trong nghiên cứu. Nghiên cứu được sự chấp thuận của đối tượng tham gia nghiên cứu và bệnh viện tiến hành nghiên cứu. Đề cương, biểu mẫu nghiên cứu được Hội đồng đạo đức trong nghiên cứu y sinh học của Viện nghiên cứu $Y$ học Đinh Tiên Hoàng phê duyệt (theo số IRB-VN02010-10/2015).

\section{KẾT QUẢ NGHIÊN CỨU}

Đặc điểm đối tượng nghiên cứu

Bảng 1: Đặc điếm cơ bản của người tham gia nghiên cứu

\begin{tabular}{|c|c|c|c|}
\hline $\begin{array}{l}\text { Thông tin } \\
\text { chung }\end{array}$ & & $\begin{array}{l}\text { T'ân số } \\
(n=15)\end{array}$ & $\begin{array}{l}\text { Tỷ lệ } \\
(\%)\end{array}$ \\
\hline \multirow{2}{*}{ Tuổi } & $\leq 30$ tuối & 4 & 26,7 \\
\hline & >30 tuối & 11 & 73,3 \\
\hline \multirow{2}{*}{ Giới } & Nam & 5 & 33,3 \\
\hline & Nữ & 10 & 66,6 \\
\hline \multirow{3}{*}{$\begin{array}{l}\text { Vị trí } \\
\text { công tác }\end{array}$} & Điều dưỡng & 7 & 46,7 \\
\hline & Bác sĩ & 6 & 40 \\
\hline & $\begin{array}{l}\text { Khác (lao công, } \\
\text { phiên dịch viên) }\end{array}$ & 2 & 13,3 \\
\hline \multirow{2}{*}{$\begin{array}{l}\text { Tình trạng } \\
\text { hôn nhân }\end{array}$} & Độc thân & 3 & 20 \\
\hline & Kết hôn & 12 & 80 \\
\hline \multirow{2}{*}{$\begin{array}{l}\text { Phơi nhiềm } \\
\text { với COVID-19 }\end{array}$} & Có & 12 & 80 \\
\hline & Không & 3 & 20 \\
\hline
\end{tabular}

Đối tượng tham gia nghiên cứu hầu hết là nữ giới chiếm $66,6 \%$ và đã kết hôn chiếm $80 \%$. Chủ yếu đối tượng tham gia là người trực tiếp tiếp xúc, chăm sóc và điêu trị bệnh nhân COVID-19 chiếm tỷ lệ cao $80 \%$. Các yếu tố thúc đẩy công việc của NVYYT trong đại dịch COVID-19.

Các yếu tố được cho là động lực nảy sinh từ lời tường thuật của người tham gia phỏng vấn bao gồm cá nhân, mối quan hệ giữa các cá nhân, môi trường bên ngoài như bệnh viện, xã hội, chính sách nhà nước và dịch bệnh.

Trách nhiệm trong công việc và đạo đức nghề y. Cuộc phỏng vấn cho thấy trách nhiệm trong công việc và đạo đức nghề y là nền tảng thúc đẩy NVYT trong công tác tham gia chống dịch. Việc được thể hiện vai trò của mình trong xã hội và mong muốn đẩy lùi dịch bệnh, bảo vệ 
sức khỏe của nhân dân luôn tạo thành những yếu tố động lực tốt nhất ngay cả khi tính mạng của ho bi đe doa.

"Với em chống dịch nó là trách nhiệm là công việc phải làm" (BS Th, nam, 35 tuổi)

"Động lực cho mình chắc là tình yêu nghề. Ngay lúc đi học mình đã thích môn truyền nhiễm, sau ra trường cũng xác định vào viện truyền nhiễm luôn, cũng trả hiểu vì sao, chắc là vì yêu nghề, cái duyên với nghề" (BS Th, nam, 28 tuối)

"Bọn chị luôn trong tinh thần chuẩn bị, sẵn sàng chờ đến lượt mình khi mà có bất cứ diễn biến xấu như là: bệnh nhân tăng lên, Điều dưỡng sức khỏe có vấn đề, thiếu người,con nhỏ,... tất cả đều rất là sẵn sàng." (BS H, nữ, 31 tuổi)

* Yếu tố chuyên môn. Trong cuộc phỏng vấn, đã có bác sĩ, điều dưỡng nhận định vai trò của chuyên môn đã hỗ trợ rất nhiều giúp họ hoàn thành công việc.

"Trong quá trình bắt đầu điều trị cho đến khi dịch đạt đỉnh điểm, chuyên môn đã tạo điều kiện thuận lợi trong suốt cả quá trình chống dịch" (BS Th, nam, 35 tuổi).

"Giai đoạn đầu mới điều trị bệnh nhân thì bọn em cũng lo lắng lắm, những sau đó quen dần, mình cũng được hướng dẫn đào tạo rồi khi chăm sóc tiếp xúc với bệnh nhân nâng cao tinh thân nên sự lo lắng cũng giảm bớt đi rất nhiều" (BS Th, nữ, 32 tuổi)

* Đônng nghiệp. Trong các cuộc phỏng vấn, làm việc trong tình trạng khẩn cấp, nguy cơ cao bị lây nhiễm đã củng cố và tạo điều kiện thuận lợi cho các mối quan hệ đồng nghiệp phát triển.

"Bon em ở trong này coi nhau như gia đình. Bọn em không chỉ hỗ trợ về chuyên môn, còn động viên nhau cố gắng" (ĐD Th, nữ, 32 tuổi)

"Trong quá trình chưa đủ thời gian hết cách thì mình lại vào điều trị tiếp thay cho đồng nghiệp khác để mọi người đỡ mệt. Nên gần như trong xuất quá trình chống dịch mình không có ra ngoài" (BS Th, nam, 35 tuổi)

"Thực ra, bây giờ mình làm trực tiếp ý, mình thây mức độ nguy hiểm của nó, nó dễ lây lan, kể cả đội mới đi sang đợt này cũng thế. Tất cả bọn mình cũng động viên nhau cố gắng chống dịch, hết dịch là được về nhà rồi" (ĐD Ch, nữ, 35 tuổi)

* Gia đình. Các đối tượng đều cho rằng gia đình hiểu cho công việc và luôn hỗ trợ họ trong giai đoạn khủng hoảng. Đặc biệt đối với những NVYT có con nhỏ, bố mẹ và chồng là những người hỗ trợ rất nhiêu trong công việc nhà để họ hoàn thành trách nhiệm của một NVYT.

"Bé nhà em mới gần một tuổi nhưng cũng may mắn thay tuy thiếu bố nhưng lại được mẹ ở nhà chăm bạn ấy $100 \%$. Cơ bản về phía gia đình cũng không phải lo lắng gì cả yên tâm 100\% chống dịch" (BS Th, nam, 35 tuổi)

"Bố mẹ, chồng cũng an ủi, động viên mình rất nhiều. Đây là nguồn động viên lớn nhất dành cho mình" (BS H, nữ, 30 tuổi)

"Cảm xúc thứ nhất là cũng yên tâm bởi vì các công việc ở nhà cũng được đảm bảo, cho mình yên tâm ở trong này, gia đình đều động viên." (Phiên dịch viên $\mathrm{N}$, nam, 33 tuổi)

* Người bệnh. Mối quan hệ giữa bệnh nhân và NVYT tạo động lực cho họ làm việ̂c. Những lời cảm ơn từ chính bệnh nhân nhiểm COVID-19 được các đối tượng tham gia phỏng vấn đề cập như động lực giúp họ làm việc. Ngoài ra những diễn biển về sức khỏe của bểnh nhân có ảnh hưởng lớn đến tâm trạng của cán bộ nhân viên.

"Hầu hết bệnh nhân ra viện khỏi cách ly, họ thường gọi điện lại, động viên mọi người . Họ rất biết ơn mình đã đồng hành cùng họ. Đó là những điều động viên to lớn đối với bọn mình" (BS TA, nam, 54 tuổi)

"Tâm trạng nói chung vui lắm, những $\mathrm{ca}$ bệnh nào trả kết quả về âm tính thị mừng lắm....Bệnh nhân vào đây nói chung đa phần cũng rất hợp tác, nên bọn em cũng không có khó khăn gì hay áp lực gì" (ĐD A, nữ, 28 tuổi)

* Từ phía bệnh viện. Bệnh viện đã chuẩn bị phương tiện phòng hộ, hướng dẫn và quy trình kiểm soát lây nhiễm, phân chia công việc và những hỗ trợ đền đời sống cho nhân viên.

"Mọi chế độ đều tốt cả, về trang phục bảo hộ, về động viển, về phân công, việc phẩn chia quà cáp, quyền lợi, đi du lịch các thứ đều ổn cả." (Kỹ thuật viên $H$, nữ, 31 tuổi)

"Trước khi phòng chống dịch, lãnh đạo khoa đã họp lại, chuẩn bị tâm lý rất kỹ cho nhân viên." ( ĐD T, nam, 28 tuổi)

"Ăn uống thì tất nhiên không bằng được ở nhà. Nhưng bác giám đốc viện quan tâm lắm, bác xuống tân nơi hỏi thăm, xem khẩu phần ăn, thay đổi chố ăn và thực đơn thường xuyên. Nói chung là bệnh viện quan tâm nên cũng vui hơn rất nhiều" (ĐD L, nữ, 32 tuổi)

* Chính sách và hố trợ nhà nước. Các chính sách đúng đắn của nhà nước thời điểm đó đã củng cố niềm tin cho NVYT, giúp họ an tâm trong công tác khám chữa bệnh.

"Mình có một niềm tin, tại thời điểm đó Bác Đam đã làm rất tốt, sau đó bên quân đội đã có những biện pháp cách ly hiệu quả. Có một chuyến xe chở người Trung Quốc chạy thẳng vào Hội An mà mình cũng bắt và trục xuất được. Nên 
là trong thời điểm đấy mình yên tâm về mọi thứ" (BS Th, nam, 35 tuổi)

* Xã hội. Ngoài các hỗ trợ từ phía bệnh viện và nhà nước, đại dịch COVID-19 đã mang lại nhiều giá trị hơn về tinh thần đồng bào dân tộc, cùng nhau chống dịch.

"Bọn mình được người dân ủng hộ đồ ăn,nước uống. Với những lời chúc chúc và cảm ơn những anh chị áo trắng. Bọn mình rất vui, còn chụp ảnh đăng facebook để cảm ơn mọi người" (ĐD A, nữ, 26 tuổi)

"Mọi người cũng chia sẻ bày tỏ sự quan tâm như bây giờ ở trên tủ lạnh ở bệnh viện bệnh nhiệt đới trung ương cơ sở 2 vẫn còn dán nhửng cái lời chúc, hỏi thăm từ những người gửi trà sữa đến làm kỷ niệm cũng động viên mọi người rất là nhiều" (BS PM, nữ, 52 tuổi)

Các yếu tố tác động tiêu cực đến NVYT trong đại dịch COVID-19.

* Yếu tố chuyên môn. Trong nghiên cứu này, đối tượng tham gia nghiên cứu là nhân viên phòng kế hoạch tổng hợp, lao công, phiên dịch viên là những người không có chuyên môn về y học sẽ có những lo lắng hơn so với các đối tượng phỏng vấn khác.

"Dịch không biết lây như thế nào ấy, không biết con ây tồn tại thời gian bao lâu mình cũng không được nắm rõ nên là cũng hoang mang" (Lao công D, nữ, 46 tuổi)

"Sợ và hoang mang khi đọc thông tin, tìm hiểu về con virus này cũng sợ lắm. Sợ bởi vì là vào đây chắc chắn phải tiếp xúc gần, nguy cơ lây cũng là rất cao." (Phiên dịch viên N, nam, 31 tuổi)

Bên cạnh đó, một số Điều dưỡng là quản lý, lãnh đạo bệnh viện chia sẻ những lo lắng băn khoăn về sự mới và đặc thù do đại dịch COVID19 mang lại.

"Thời gian đó cũng có rất nhiều tranh cãi trong quá trình điều trị vì con virus này rất mới. Đối với một người lãnh đạo như chị lúc ấy rất là căng thẳng với những cái phác đồ điêuu trị, mình phải có những cập nhật." (ĐD PM, nữ, 52 tuổi).

* Yếu tố gia đình. Bên cạnh những tác động tích cực từ phía gia đình. Tंrong 15 người tham gia phỏng vấn có 13 người đã kết hôn trong đó hầu hết đều đề cập đến vấn đề gia đình điển hình là con cái, me già ở nhà không có người chăm sóc gây ra nỗi nhớ mong, tâm trạng lo lắng của hầu hết các đối tượng.

"Nhiều lúc em nghĩ cũng tủi, vừa nhớ gia đình vừa nhớ con, nhất là hai vợ chồng ở cùng trong này, nhớ con kinh khủng luôn... Em bị mất ngủ cả mây tuần, nhớ con thương chồng một mình lủi thủi ở nhà, xong sau đó chồng em cũng đi chống dịch. Mặc dù cùng một viện, nhưng hai đứa em chỉ có nhìn nhau qua khung cửa kính. Nói chung là buồn lắm" ( $Đ D$ Th, nữ, 28 tuổi)

"Mình có con nhỏ, bé vẫn còn đang dùng sữa. Mình đã phải cai sữa luôn cho bé. Bé khóc nhiều lắm (Khóc), mình chưa bao giờ xa nó lâu như thế. Mỗi lần gọi điện con nhìn thấy mẹ lại khóc, mình cũng đã khóc rất nhiều" (ĐD L, nữ, 32 tuổi).

"Thời gian đầu, nửa đêm con khóc đòi mẹ. Hai vợ chồng mình chống dịch trên này nhưng khác khhoa, ông bà gọi điện lên cho bọn mình. Hai mẹ con cứ khóc, nhìn con khóc, vợ khóc, lúc đó mình chán lắm" ( $Đ D T$, nam, 28 tuổi)

* Yếu tố xã hội. Cuộc phỏng vấn nổi lên những tác động tiêu cực từ phía xã hội ảnh hưởng đến tâm lý và đời sống của NVYT trong thời gian đại dịch COVID-19 diển ra.

"Nói chung là cảm giác như bị công đồng xa lánh, nhiêu lúc nghĩ cũng chán cũng buồn lắm. Con mình đi học, chồng còn dặn là nếu cô có hỏi bố mẹ làm ở đâu thì bảo làm công nhân bình thường thôi, không lại sợ con bị kỳ thị các thứ" (ĐD Th, nữ, 28 tuổi)

"Hàng xóm, mọi người cũng kỳ thị vì mọi người cứ nghĩ là mình làm ở bệnh viện bệnh nhiệt đới là có nguy cơ lây bệnh rồi" (ĐD H, nữ, 30 tuổi)

"Mình chỉ mong cộng đồng đừng kỳ thị NVYT. Bọn mình đi làm cũng đã rất mệt mỏi, bọn mình đi siêu thị hay mua đồ cần thiết dù đã rất hạn chế, cẩn thận nhưng vẫn rất sợ không may xã hội lên án" (ĐD H, nữ, 31 tuổi)

\section{BÀN LUẬN}

Đối tượng tham gia nghiên cứu có đặc điểm chung khá tương đồng so với nghiên cứu định tính đã thực hiện tại Ỳ, đa số là nữ giới, đã có gia đình với tuổi trung bình trên 30 tuổi. Bên cạnh đó do đây là nghiên cứu định tính và quy định phòng ngừa lây nhiễm cho nên cỡ mẫu nhỏ hơn khá nhiều so với các nghiên cứu định lượng khác, tuy nhiên, cỡ mẫu nghiên cứu tương đồng với nghiên cứu định tính tại Ý [3], [4].

Một số yếu tố tích cực đến NVYT trong đại dịch COVID-19 được nghiên cứu của chúng tổi chỉ ra bao gồm: trách nhiệm, đạo đức nghề $\mathrm{y}$, chuyên môn, mối quan hệ với gia đình, đồng nghiệp, bệnh nhân và yếu tố hố trợ từ bệnh viện, xã hội . Kết quả này tương đồng như nghiên cứu của Amalia De Leo năm 2021 phỏng vấn định tính 17 NVYT [3]. Cả hai nghiên cứu định tính của Amalia De Leo và Henry Aughterson đều nhận định hai yếu tố cá nhân 
bao gồm trách nhiệm, đạo đức nghề ý và yếu tố chuyên môn có tác động tích cực đến NVYT [3], [4]. Điều này có thể dễ dàng lý giải khi các nghiên cứu đã chỉ ra NVYT tin rằng họ có nghĩa vụ với xã hội và đây là động lực để họ tiếp tục làm việc [5]. Trình độ chuyên môn, kiến thức về dịch bệnh giúp họ dễ dàng thích nghi hơn với các vấn đề cấp bách do đại dịch mang lại [3].

Mối quan hệ giữa các cá nhân cho thấy sự giúp đõ̃ từ phía gia đình giúp cho NVYT an tâm hơn trong quá trình phòng chống dịch đã được chỉ ra ở nhiêuu nghiên cứu [3], [5]. Ngoài ra, đại dịch COVID-19 đã được nhấn mạnh ở nhiều nghiên cứu cho thãy nó làm nổi bật nên mối quan hệ đồng nghiệp, sự trợ giúp lẫn nhau trong công việc và động viên trong đời sống hàng ngày [3], [4], [5]. Một trong những mối quan hệ mật thiết của NVYT trong quá trình chống dịch chính là mối quan hệ với bệnh nhân. Nghiên cứu của chúng tôi chỉ ra sư hợp tác và diễn biến bệnh tật tốt hơn của bệnh nhân giúp cho NVYT có thể hoàn thành công việc tốt hơn và có tâm lý tốt hơn, tương tự các nghiên cứu trước đây [4], [5], [6]. Tuy nhiên có một số nghiên cứu có sự khác biệt khi nhấn mạnh vai trò dãn cách, chiến lược tự bảo vệ để tránh tiếp xúc gần và những cảm xúc bất lực có thể xảy ra ảnh hưởng đến sức khỏe cũng như chuyên môn của họ [3].

Các yếu tố từ phía bệnh viện, nhà nước và xã hội là những động lực đóng vai trò quan trọng khi đã được đề cập đến hầu hết trong các nghiên cứu trước đây [4], [5], [6]. Tuy nhiên, có thể lý giải khi hầu hết các yếu tố từ phía bệnh viện ,nhà nước được nghiên cứu của chúng tôi chỉ ra mang lại ý nghĩa tích cực bởi thành quả trong công tác phòng chống dịch tại Việt Nam đã được thễ giới công nhận với những quyết sách đúng đắn của nhà nước và sự đồng lòng của người dân. Trong khi đó ở các nước khác, dịch bênh diễn ra phức tap hơn, cùng với đó là đặc điểm chính trị văn hóa khác biệt nên bên cạnh những mặt tích cực các nghiên cứu hầu hết đều đề cập đển một số những ảnh hưởng tiêu cực về phía bệnh viện và nhà nước đến NVYT [3], [4], [5].

Ba yễu tố tại nghiên cứu của chúng tôi được đề cập như là yếu tố tiêu cực ảnh hưởng đến NVYT bao gồm: yếu tố chuyển môn, yếu tố gia đình và yếu tố xã hội. Amalia De Leo có cùng nhân định như nghiên cứu của chúng tôi và có thể dễ dàng lý giải cho yếu tố này khi những người không có chuyên môn về dịch bệnh họ không có năng lực về lâm sàng để hoàn thành tốt công việc [3], [7]. Những NVYT có con nhỏ hoặc còn những nối lo về gia đình sẽ ảnh hưởng trực tiếp đến quá trình làm việc của họ [3], [5]. Ngoài ra một yếu tố được nhẩn mạnh cho là có tác động tiểu cực được đề cập đến đó là sự kỳ thị của xã hội [8]. Nghiên cứu của chúng tôi cũng như các nghiên cứu khác cho thấy NVYT bị xã hội cô lập và kỳ thị, họ gặp khó khăn trong vấn đề sinh hoạt đời sống hàng ngày, chỗ ở,... [8]. Điều này lý giải cho hầu hết những hành động của NVYT khi họ quyết đình ở lại bệnh viện sau khi hết cách ly, hạn chế ra ngoài và tự cách ly bản thân để tránh sự kỳ thị của xã hội.

\section{KẾT LUẬN}

Yếu tố ảnh hưởng tích cực đến công việc của NVYT là trách nhiệm và đạo đức nghề y; chuyên môn; mối quan hệ xã hội như hỗ trợ từ gia đình, đồng nghiệp, sự hợp tác của bệnh nhân và chính sách, hố trợ nhà nước, xã hội. Yếu tố tác động tiêu cực là gia đình có con nhỏ; không làm chuyên môn và sự kỳ thị của xã hội. Cân tăng cường hơn nữa những hỗ trợ về tâm lý, vật chất cho nhân viên và người nhà của họ nhằm nâng cao chất lượng công việc và đời sống tinh thần của NVYT trong thời kỳ chống dịch.

\section{TÀI LIÊU THAM KHẢO}

1. Bộ Y tế (2021). Trang tin về dịch bệnh viêm đường hô hấp cấp Covid-19. Truy cập ngày 05/24/2021. Tại trang web https://moh.gov.vn

2. Elbarazi I., Loney T., Yousef S., et al. (2017). Prevalence of and factors associated with burnout among health care professionals in Arab countries: a systematic review. BMC Health Serv Res, 17, 2319.

3. De Leo A., Cianci E., Mastore $P_{. \prime}$ et al. (2021). Protective and Risk Factors of Italian Healthcare Professionals during the COVID-19 Pandemic Outbreak: A Qualitative Study. Int J Environ Res Public Health, 18(2), 453.

4. Aughterson H., McKinlay A.R., Fancourt D., et al. (2021). Psychosocial impact on frontline health and social care professionals in the UK during the COVID-19 pandemic: a qualitative interview study. BMJ Open, 11(2), 047353.

5. Cai H., Tu B., Ma J., et al. (2020). Psychological Impact and Coping Strategies of Frontline Medical Staff in Hunan Between January and March 2020 During the Outbreak of Coronavirus Disease 2019 (COVID-19) in Hubei, China. Med Sci Monit Int Med J Exp Clin Res, 26, e924171-1-e924171-16.

6. Arnetz J.E., Goetz C.M., Arnetz B.B., et al. (2020). Nurse Reports of Stressful Situations during the COVID-19 Pandemic: Qualitative Analysis of Survey Responses. Int J Environ Res Public Health, 17, 8126.

7. Elbay R.Y., Kurtulmuş A., Arpacıoğlu S., et al. (2020). Depression, anxiety, stress levels of physicians and associated factors in Covid-19 pandemics. Psychiatry Res, 290, 113130.

8. Bagcchi S. (2020). Stigma during the COVID-19 pandemic. Lancet Infect Dis, 20(7), 782. 